\title{
Genetic diversity and geographical differentiation of cultivated six-rowed naked barley landraces from the Qinghai-Tibet plateau of China detected by SSR analysis
}

\author{
Zong-Yun Feng ${ }^{1,2,3}$, Li-Li Zhang ${ }^{3}$, Yi-Zheng Zhang ${ }^{1}$ and Hong-Qing Ling ${ }^{2}$ \\ ${ }^{1}$ Sichuan University, College of Life Sciences, Key Laboratory of Molecular Biology \& Biotechnology, \\ Chengdu, China. \\ ${ }^{2}$ Chinese Academy of Sciences, Institute of Genetics \& Developmental Biology, The State Key Laboratory \\ of Plant Cell \& Chromosome Engineering, Beijing, China. \\ ${ }^{3}$ Sichuan Agricultural University, College of Agronomy, Yaan, China.
}

\begin{abstract}
Cultivated six-rowed naked barley (Hordeum vulgare ssp. hexastichon var. nudum Hsü) is the oldest cultivated barley in China. We used 35 simple sequence repeat (SSR) markers selected from seven barley linkage groups to study the genetic diversity, geographical differentiation and evolutionary relationships among $65 \mathrm{H}$. vulgare ssp. hexastichon landrace accessions collected from the Qinghai-Tibet plateau of China, 25 accessions from Tibet (TB), 20 from Qinghai (QH) and 20 from Ganzi (GZ) prefecture in Sichuan province. At the 35 SSR loci we identified 248 alleles among the 65 accessions, $119(47.98 \%)$ of the alleles being common alleles. We also found that the TB accessions possessed 47 private alleles, about 1.5 times more than the 31 private alleles found in the QH accessions and about 5 times more than 9 private alleles found in the GZ accessions. Generally, the TB accessions showed significantly higher genetic diversity than either the QH or GZ accessions whereas no significant difference in genetic diversity was found between the QH and GZ accessions. Partitioning analysis of genetic diversity showed that about $81 \%$ of the total variation was due to within-subgroup diversity and about $19 \%$ was clearly accounted for by geographical differentiation among the three subgroups. The distributions of alleles for most loci $(71.4 \%)$ were significantly different among the three subgroups and geographical differentiation could be found according to the distribution of SSR alleles. Cluster analysis indicated that most of the accessions could be clustered into groups which basically coincided with their geographical distribution. These results suggest that Tibet might be a center of genetic diversity for cultivated barley, the cultivated six-rowed naked barley on the Qinghai-Tibet plateau of China may have evolved in Tibet and spread to Qinghai and then to Ganzi prefecture of Sichuan province.
\end{abstract}

Key words: Barley, genetic diversity, Qinghai-Tibet plateau, geographical differentiation, simple sequence repeat marker.

Received: March 3, 2005; Accepted: September 21, 2005.

\section{Introduction}

Barley (Hordeum vulgare L.) is one of the oldest cultivated crops in the world and studying genetic diversity and evolutionary relationships in barley is important for the effective conservation and utilization of barley genetic resources. Early studies suggested that there were two original centers of cultivated barley, one in the Fertile Crescent (Ancient Egypt, the Levant and Mesopotamia) as indicated by the widespread dispersion of Hordeum spontaneum

Send correspondence to Hong-Qing Ling. Chinese Academy of Sciences, Institute of Genetics \& Developmental Biology, The State Key Laboratory of Plant Cell \& Chromosome Engineering, Datun Road, Chaoyang District, Beijing 100101, China. E-mail: hqling@ genetics.ac.cn.
Koch, the nearest wild ancestor of two- and six-rowed cultivated barley, in this region (Harlan, 1976) and another in the Tibetan region of China on the Qinghai-Tibet plateau ('the roof of the world') supported by the discovery of Hordeum agriocrithon Åberg, a six-rowed wild barley considered an ancestor of two- and six-rowed cultivated barley (Vavilov, 1926; Åberg, 1938; Brücher and Åberg, 1950).

Many studies have demonstrated that Tibetan wild barley populations were clearly different from the Fertile Crescent wild barley in respect to their distribution, ecology, morphology, archaeology, cytogenetics and isozyme complement (Xu, 1975, 1982; Zhou, 1981; Shao, 1982; Yao, 1982). This supports the hypothesis of separate evolutionary systems leading to Tibetan two-rowed wild barley becoming the ultimate progenitor of Chinese cultivated 
barley, Tibetan six-rowed wild barley being an intermediate form in the processes of transforming two-rowed wild barley to six-rowed cultivated barley (Xu, 1982). Naked barley (Hordeum vulgare var. nudum), also called Qingke, is a major food used to produce 'Zanba' by ethnic Zangs inhabiting the Qinghai-Tibet plateau of China. Cultivated six-rowed naked barley (H. vulgare ssp. hexastichon var. nudum Hsü) is the earliest cultivated barley in China (Fu et al., 2000; Xu and Feng, 2001). Evidently, study on genetic diversity and geographical differentiation of cultivated six-rowed naked barley landraces from the Qinghai-Tibet plateau will be useful in understanding the evolutionary relationship of barley.

At present, most studies on the genetic diversity and evolution of cultivated barley from the Qinghai-Tibet plateau of China have dealt with morphology (Xu, 1986), botanical classification (Xu, 1982), cytogenetics (Yao, 1982; Shao, 1986) and isozymes (Shao, 1986; Dai and Zhang, 1989; Zhang et al., 1992a, 1994; Sun et al., 1995). However, some researchers have used DNA molecular markers, including restriction fragment length polymorphisms (RFLP) (Zhang et al., 1992b, 1994), random amplified polymorphic DNA (RAPD) (Hong et al., 2001) and ribosomal DNA spacer-length techniques (Li et al., 2003), although, except for Tibetan landraces, cultivated six-rowed naked barley landraces from the Qinghai-Tibet plateau have rarely been included in such studies. Simple sequence repeat (SSR), or microsatellite, analysis possess a number of advantages over other forms of genetic analysis, including a high level of polymorphisms, locus specificity, codominance, reproducibility, random distribution throughout the genome and is also methodologically simple (Saghai-Maroof et al., 1994; Feng et al., 2002). Techniques based on SSR technology are useful in evaluating and characterizing genetic diversity, phylogenetic development and evolution as well elucidating the relationships within and between species and populations of members of the genus Hordeum (Saghai-Maroof et al., 1994; Russell et al., 1997; Davila et al., 1998; De Bustos et al., 1999; Fernández et al., 2002; Zhang et al., 2002; Feng et al., 2003).

In the research described in this paper we used SSR markers covering the seven barley SSR linkage groups (Liu et al., 1996) to investigate the genetic diversity and geographical differentiation of 65 cultivated six-rowed naked barley landraces collected from the Qinghai-Tibet plateau of China.

\section{Materials and Methods}

\section{Plant materials}

In this study we used 65 landrace accessions (Table 1) of the cultivated six-rowed naked barley $H$. vulgare L. ssp. hexastichon var. nudum Hsü (hereafter denominated as nudum barley) from different geographical locations on the Qinghai-Tibet plateau of China, of which 25 accessions were from Tibet (TB), 20 from Qinghai $(\mathrm{QH})$ and 20 from Ganzi (GZ) prefecture in Sichuan province. Seeds of the different accessions were kindly provided by the following people: TB accessions by Mr. QIANG Xiao-Lin (Institute of Agricultural Sciences, Tibetan Academy of Agricultural \& livestock Sciences); QH accessions by Prof. SUN Li-Jun (Institute of Crop Germplasm Resources, Chinese Academy of Agricultural Sciences); and GZ accessions by Mr. YANG Kai-Jun (Ganzi Institute of Agricultural Sciences in Sichuan province).

\section{Genomic DNA extraction}

The cetyltrimethylammonium bromide (CTAB) method (Stein et al., 2001) was used to extract total DNA from about $300 \mathrm{mg}$ of young leaf-tissue of each accession. The quality of the DNA was checked using agarose-gel electrophoresis and the DNA concentration estimated spectrophotometrically and the solution diluted with distilled water to a final working DNA concentration of $20 \mathrm{ng} \mu \mathrm{L}^{-1}$.

\section{PCR amplification, electrophoresis and silver staining}

We selected 35 simple sequence repeats (SSRs) (Table 2), five from each chromosome, from the genetic maps described by Liu et al. (1996). The primers were synthesized by a commercial company (AuGCT Biotechnology, Beijing, China). The polymerase chain reaction (PCR) was carried out in a final volume of $15 \mu \mathrm{L}$ containing $2 \mu \mathrm{L}$ of the $20 \mathrm{ng} \mu \mathrm{L}^{-1}$ genomic DNA solution described above (template DNA), $1.5 \mu \mathrm{L}$ of 10xPCR buffer containing $15 \mathrm{mM}$ $\mathrm{Mg}^{2+}, 1.5 \mu \mathrm{L}$ of a $2.5 \mathrm{mM}$ dNTP mixture, 0.5 units of rTaq DNA polymerase (TaKaRa Biotechnology, Dalian, China) and $1 \mu \mathrm{L}$ of a $2 \mu \mathrm{M}$ solution of the forward and reverse primers. Depending on the primer pair used, DNA amplifications were performed in a thermocycler using one of the following five PCR protocols: (1) A touchdown PCR reaction consisting of 18 cycles of a $94{ }^{\circ} \mathrm{C}$ denaturing step for $1 \mathrm{~min}$ and $\mathrm{a} 72{ }^{\circ} \mathrm{C}$ for $1 \mathrm{~min}$ extension, followed by annealing for $30 \mathrm{~s}$ with the temperatures decreasing by $1^{\circ} \mathrm{C}$ every two cycles from $64{ }^{\circ} \mathrm{C}$ to $55^{\circ} \mathrm{C}$. The PCR reaction continued for 30 additional cycles at $94{ }^{\circ} \mathrm{C}$ for $1 \mathrm{~min}, 55^{\circ} \mathrm{C}$ for $1 \mathrm{~min}$ and $72^{\circ} \mathrm{C}$ for $1 \mathrm{~min}$. The reaction ended with a 5 -min extension at $72{ }^{\circ} \mathrm{C}$. (2) A similar touchdown procedure to the above protocol except that the annealing temperatures were decreased from $69{ }^{\circ} \mathrm{C}$ to $60^{\circ} \mathrm{C}$ for 18 cycles, at which temperature the reaction continued for 20 additional cycles. (3) A normal PCR protocol consisting of one cycle of $94{ }^{\circ} \mathrm{C}$ for $3 \mathrm{~min}, 55^{\circ} \mathrm{C}$ for $2 \mathrm{~min}$ and $72{ }^{\circ} \mathrm{C}$ for $1.5 \mathrm{~min}$, followed by 30 cycles at $94^{\circ} \mathrm{C}$ for $1 \mathrm{~min}, 55^{\circ} \mathrm{C}$ for $2 \mathrm{~min}$ and $72{ }^{\circ} \mathrm{C}$ for $1.5 \mathrm{~min}$. (4) Denaturing for $5 \mathrm{~min}$ at $95{ }^{\circ} \mathrm{C}$ followed by 42 cycles at $92{ }^{\circ} \mathrm{C}$ for $1 \mathrm{~min}, 60^{\circ} \mathrm{C}$ for $1 \mathrm{~min}$, $72^{\circ} \mathrm{C}$ for $1 \mathrm{~min}$, and ending with a final 10 -min elongation at $72^{\circ} \mathrm{C}$. (5) 35 reaction cycles of $96^{\circ} \mathrm{C}$ for $1 \mathrm{~min}, 60^{\circ} \mathrm{C}$ for 
Table 1 - List and origin of cultivated six-rowed naked barley (nudum barley) landraces collected from the Qinghai-Tibet plateau of China used in this study.

\begin{tabular}{|c|c|c|c|c|c|c|c|c|}
\hline \multicolumn{3}{|c|}{$\begin{array}{l}\text { Tibetan autonomous region } \\
\text { (coded as TB in the text) }\end{array}$} & \multicolumn{3}{|c|}{$\begin{array}{l}\text { Qinghai province } \\
\text { (coded as QH in the text) }\end{array}$} & \multicolumn{3}{|c|}{$\begin{array}{l}\text { Ganzi prefecture of Sichuan province } \\
\text { (coded as GZ in the text) }\end{array}$} \\
\hline Code & National code & $\begin{array}{l}\text { County } \\
\text { of origin }\end{array}$ & Code & National code & $\begin{array}{l}\text { County } \\
\text { of origin }\end{array}$ & Code & National code & $\begin{array}{l}\text { County } \\
\text { of origin }\end{array}$ \\
\hline 107 & ZDM4998 & Milin & 132 & ZDM8088 & Yushu & 152 & ZDM3829 & Danba \\
\hline 108 & ZDM5627 & Naidong & 133 & ZDM8093 & Yushu & 153 & ZDM3830 & Yajiang \\
\hline 109 & ZDM5855 & Qiongjie & 134 & ZDM8096 & Nangqian & 154 & ZDM3834 & Kangding \\
\hline 110 & ZDM5688 & Nielamu & 135 & ZDM8098 & Nangqian & 155 & ZDM3843 & Yajiang \\
\hline 111 & ZDM5997 & Chayu & 136 & ZDM8115 & Chengduo & 156 & ZDM3837 & Kangding \\
\hline 112 & ZDM5139 & Zuogong & 137 & ZDM8181 & Maqin & 157 & ZDM3847 & Kangding \\
\hline 113 & ZDM6019 & Milin & 138 & ZDM8183 & Maqin & 158 & ZDM3835 & Ganzi \\
\hline 114 & ZDM5927 & Dazi & 139 & ZDM8135 & Chengduo & 159 & ZDM3844 & Ganzi \\
\hline 115 & ZDM5941 & Sajia & 140 & ZDM8196 & Chengduo & 160 & ZDM3841 & Batang \\
\hline 116 & ZDM5950 & Xietongmen & 141 & ZDM8200 & Chengduo & 161 & ZDM3854 & Batang \\
\hline 117 & ZDM5964 & Longzi & 142 & ZDM8212 & Nangqian & 162 & ZDM3857 & Batang \\
\hline 118 & ZDM5901 & Dazi & 143 & ZDM8139 & Yushu & 163 & ZDM3863 & Batang \\
\hline 119 & ZDM5720 & Sangri & 144 & ZDM8142 & Banma & 164 & ZDM3859 & Litang \\
\hline 120 & ZDM5752 & Ritu & 145 & ZDM8110 & Yushu & 165 & ZDM3862 & Daocheng \\
\hline 121 & ZDM5844 & Gongga & 146 & ZDM8160 & Banma & 166 & ZDM3853 & Xiangcheng \\
\hline 122 & ZDM5874 & Bianba & 147 & ZDM8112 & Yushu & 167 & ZDM3880 & Daofu \\
\hline 123 & ZDM5693 & Qusong & 148 & ZDM8144 & Yushu & 168 & ZDM3839 & Xinlong \\
\hline 124 & ZDM5753 & Duilongdeqing & 149 & ZDM8184 & Yushu & 169 & ZDM3848 & Derong \\
\hline 125 & ZDM5781 & Rikaze & 150 & ZDM8201 & Yushu & 170 & ZDM3867 & Shiqu \\
\hline 126 & ZDM5696 & Chaya & 151 & ZDM8223 & Yushu & 171 & ZDM3882 & Jiulong \\
\hline 127 & ZDM6148 & Lang & & & & & & \\
\hline 128 & ZDM5751 & Longzi & & & & & & \\
\hline 129 & ZDM5999 & Luolong & & & & & & \\
\hline 130 & ZDM5883 & Chaya & & & & & & \\
\hline 131 & ZDM5914 & Dazi & & & & & & \\
\hline
\end{tabular}

$1 \mathrm{~min}$ and $72{ }^{\circ} \mathrm{C}$ for $2 \mathrm{~min}$, followed by a final extension for $10 \mathrm{~min}$ at $72^{\circ} \mathrm{C}$.

After PCR amplification $5 \mu \mathrm{L}$ of $98 \%(\mathrm{v} / \mathrm{v})$ formamide electrophoresis loading buffer containing $0.25 \%$ $(\mathrm{w} / \mathrm{v})$ bromophenol blue and $0.25 \%(\mathrm{w} / \mathrm{v})$ xylene cyanole FF were added to each reaction mixture. The PCR products were denatured and separated on $6 \%$ denaturing polyacrylamide gel with $8 \mathrm{M}$ urea and $1 \mathrm{xTBE}$ buffer running at a constant power of $60 \mathrm{~W}$ for one hour. A 50 to $1031 \mathrm{bp}$ DNA ladder (Gene Ruler ${ }^{\mathrm{TM}}$ 50bp DNA ladder, MBI Ferments) was used as a size standard and the DNA fragments were silver stained as described in Bassam et al. (1991).

\section{Data analysis}

The amplified DNA fragments of each SSR locus were assessed based on electrophoretic mobility using the Qbasic procedure of Rickwood et al. (1982) and the SSR profiles were scored for the presence (1) or absence (0) of clear bands. Genetic similarities were estimated using the
DICE coefficient, $2 \mathrm{a} /(2 \mathrm{a}+\mathrm{b}+\mathrm{c})$, where ' $\mathrm{a}$ ' refers to alleles shared between two accessions and ' $b$ ' and ' $c$ ' to alleles present in either one of the two accessions compared (Rohlf, 1993). Similarity matrix cluster analysis was used to reveal associations among accessions based on the unweighted pair group method with arithmetic averages (UPGMA) implemented using the NTSYS-pc program (Rohlf, 1993).

Genetic diversity $(H)$ was calculated with $H=1-\Sigma p_{i}^{2}$ in which $p_{i}$ is the frequency of the $i^{\text {th }}$ allele of the locus (Nei, 1973). For each locus, the frequencies of each allele in the entire sample were calculated as the expected allele frequencies, and the distribution of allelic frequencies among the three subgroups was tested using the Chi-square test (Rong et al., 1993). The genetic diversity of the entire sample $\left(H_{T}\right)$ was partitioned into components reflecting genetic distance between subgroups $\left(D_{S T}\right)$ and genetic polymorphism within subgroups $\left(H_{S}\right)$, with genetic differentiation between subgroups $\left(G_{S T}\right)$ being calculated as $G_{S T}=1$ - 
Table 2 - Primer sequences, PCR conditions, repeats and chromosomal locations of simple sequence repeat (SSR) markers of barley used in this study.

\begin{tabular}{|c|c|c|c|c|c|}
\hline SSR & Primer seq & $\operatorname{ces}\left(5^{\prime} \rightarrow 3^{\prime}\right)$ & Chr. & Repeats & $\mathrm{PCR}^{\mathrm{a}}$ \\
\hline$H V M 20$ & CTCCACGAATCTCTGCACAA & CACCGCCTCCTCTTTCAC & $1 \mathrm{H}$ & $(\mathrm{AG})_{19}$ & 1 \\
\hline$H V M 43$ & GGATTTTCTCAAGAACACTT & GCGTGAGTGCATAACATT & $1 \mathrm{H}$ & $(\mathrm{CA})_{9}$ & 1 \\
\hline$H V M 63$ & CGCGCAAGCATGAATACTC & ACTCACAAGTGGCGCGTAC & $1 \mathrm{H}$ & $(\mathrm{GA})_{9}$ & 1 \\
\hline$H V M 64$ & GATGTGAAGGCTGCCTG & ACACGCCCTATTACCCAGTG & $1 \mathrm{H}$ & $(\mathrm{GA})_{4}(\mathrm{GT})_{7}(\mathrm{CT})_{2}(\mathrm{GT})_{4}(\mathrm{GA})_{8}$ & 1 \\
\hline$H V M 70$ & CCGCCGATGACCTTCTC & ACCCACGACCTATGGCAC & $1 \mathrm{H}$ & $(\mathrm{CA})_{8}$ & 3 \\
\hline$H V C S G$ & CACTTGCCTACCTCGATATAGTTTGC & GTGGATTCCATGCATGCAATATGTGG & $2 \mathrm{H}$ & $(\mathrm{CA})_{4},(\mathrm{C})_{7}$ & 4 \\
\hline HVBKASI & ATTGGCGTGACCGATATTTATGTTCA & CAAAACTGCAGCTAAGCAGGGGAACA & $2 \mathrm{H}$ & $(\mathrm{C})_{10},(\mathrm{~A})_{11}$ & 4 \\
\hline$H V M 23$ & TCGGTGAAGAAATACGAGGC & TCTTTGTGACCTACCGGTCC & $2 \mathrm{H}$ & $(\mathrm{GA})_{9}$ & 2 \\
\hline$H V M 26$ & GGCTATCACATTTGGTACCATC & GCATGTGTAGGTGTTGGTGG & $2 \mathrm{H}$ & $(\mathrm{CA})_{11}$ & 2 \\
\hline$H V M 36$ & TCCAGCCGAACAATTTCTTG & AGTACTCCGACACCACGTCC & $2 \mathrm{H}$ & $(\mathrm{GA})_{13}$ & 1 \\
\hline HVM33 & ATATTAAAAAAGGTGGAAAGCC & CACGCCCTCTCCCTAGAT & $3 \mathrm{H}$ & $(\mathrm{CA})_{7}$ & 1 \\
\hline$H V M 27$ & GGTCGGTTCCCGGTAGTG & TCCTGATCCAGAGCCACC & $3 \mathrm{H}$ & $(\mathrm{GA})_{14}$ & 1 \\
\hline$H V M 60$ & CAATGATGCGGTGAACTTTG & CCTCGGATCTATGGGTCCTT & $3 \mathrm{H}$ & $(\mathrm{AG})_{11},(\mathrm{GA})_{14}$ & 1 \\
\hline$H V M 62$ & TCGCGACCAGACGAGAAG & AGCTAGCCGACGACGCAC & $3 \mathrm{H}$ & $(\mathrm{GA})_{11}$ & 1 \\
\hline$H V M 44$ & AAATCTCAGGTTCGTGGGCA & CCACGGAGACCACCTCACTT & $3 \mathrm{H}$ & $(\mathrm{GA})_{8}$ & 1 \\
\hline$H V M 40$ & CGATTCCCCTTTTCCCAC & ATTCTCCGCCGTCCACTC & $4 \mathrm{H}$ & $(\mathrm{GA})_{6}(\mathrm{GA})_{4}(\mathrm{GA})_{7}$ & 1 \\
\hline$H V M 3$ & ACACCTTCCCAGGACAATCCATTG & AGCACGCAGAGCACCGAAAAAGTC & $4 \mathrm{H}$ & $(\mathrm{AT})_{29}$ & 3 \\
\hline$H V M 68$ & AGGACCGGATGTTCATAACG & CAAATCTTCCAGCGAGGCT & $4 \mathrm{H}$ & $(\mathrm{GA})_{22}$ & 1 \\
\hline$H V M 67$ & GTCGGGCTCCATTGCTCT & CCGGTACCCAGTGACGAC & $4 \mathrm{H}$ & $(\mathrm{GA})_{11}$ & 1 \\
\hline WMS6 & CGTATCACCTCCTAGCTAAACTAG & AGCCTTATCATGACCCTACCTT & $4 \mathrm{H}$ & $(\mathrm{GA})_{40}$ & 5 \\
\hline HVDHN7 & TTAGGGCTACGGTTCAGATGTT & ACGTTGTTCTTCGCTGCTG & $5 \mathrm{H}$ & $(\mathrm{AAC})_{5}$ & 4 \\
\hline HVDHN9 & CATGGACAAGATCAAGGAGAAG & СССАTTATTTATCTGTAGGAACGC & $5 \mathrm{H}$ & $(\mathrm{AC})_{6}$ & 4 \\
\hline$H V L E U$ & TTGGAAGTGTACAGCAATGGAG & TGAAAGGCCCCACAAGATAG & $5 \mathrm{H}$ & $(\mathrm{ATTT})_{4}$ & 4 \\
\hline HVM6 & CATGAATGAATGATTGGTTTTG & CGCATCCGTATGTATGAGTAA & $5 \mathrm{H}$ & $(\mathrm{GA})_{9}$ & 1 \\
\hline HVM30 & AGTGGGGAATGAGAGAATGG & TGCTTGTGGGTCATCACAC & $5 \mathrm{H}$ & $(\mathrm{CA})_{8}$ & 2 \\
\hline$H V M 14$ & CGATCAAGGACATTTGGGTAAT & AACTCTTCGGGTTCAACCAATA & $6 \mathrm{H}$ & $(\mathrm{CA})_{11}$ & 1 \\
\hline$H V M 34$ & ACCATGTTGCGTGTTGCTT & CGGTTCGAAATCGAGTGG & $6 \mathrm{H}$ & $(\mathrm{GA})_{10}$ & 2 \\
\hline$H V M 65$ & AGACATCCAAAAAATGAACCA & TGGTAACTTGTCCCCCAAAG & $6 \mathrm{H}$ & $(\mathrm{GA})_{10}$ & 1 \\
\hline$H V M 22$ & TTTTGGGGGATGCCTACATA & TTTCAAATGGTTGGATTGGA & $6 \mathrm{H}$ & $(\mathrm{AC})_{13}$ & 1 \\
\hline$H V M 74$ & AGGAAGTCATTGCGTGAG & TGATCAAGAATGATAACATGG & $6 \mathrm{H}$ & $(\mathrm{GA})_{13}$ & 3 \\
\hline HVM49 & CTCTATAGGCACGAAAAATTCC & TTGCACATATCTCTCTCTGTCACA & $7 \mathrm{H}$ & $(\mathrm{CA})_{12}$ & 1 \\
\hline HVCMA & GCCTCGGTTTGGACATATAAAG & GTAAAGCAAATGTTGAGCAACG & $7 \mathrm{H}$ & $(\mathrm{AT})_{9}$ & 4 \\
\hline HVM5 & AACGACGTCGCCACACAC & AGGAACGAAGGGAGTATTAAGCAG & $7 \mathrm{H}$ & $(\mathrm{GT})_{6},(\mathrm{AT})_{16}$ & 3 \\
\hline HVM4 & AGAGCAACTACCAGTCCAATGGCA & GTCGAAGGAGAAGCGGCCCTGGTA & $7 \mathrm{H}$ & $(\mathrm{AT})_{9}$ & 3 \\
\hline HVM51 & TCTAAATTACCTTCCCAGCCA & AAGCAGACATGTAGGAGGTCA & $7 \mathrm{H}$ & $(\mathrm{GA})_{3}(\mathrm{GGGA})_{3},(\mathrm{GA})_{8}$ & 1 \\
\hline
\end{tabular}

${ }^{a}$ The numbers represent one of the five PCR conditions described in the materials and methods section.

$H s / H_{T}$ (Nei, 1973). The comparisons of genetic diversity were carried out using the Z-test (Zhang and Allard, 1986; Zhang et al., 1992).

\section{Results}

\section{Allelic variation of SSRs}

Total alleles, common alleles and the number of private alleles are shown in Table 3. A total of 248 alleles were detected at the $35 \mathrm{SSR}$ loci, with an average of 7.09 alleles per locus in the entire sample. The number of alleles varied from 16 at the HVM68 locus to 2 each at the $H V M 3$, HVM44 and HVM49 loci. Seven of the 35 loci showed more than 10 alleles per locus. The alleles for the 35 loci were distributed among the three geographical location accession subgroups (TB, QH and GZ) as follows: 193 alleles for TB, 180 for $\mathrm{QH}$ and 152 for GZ. No allele was detected at the HVM44 locus in the $\mathrm{QH}$ accessions and HVM14 locus in the GZ accessions and only one allele each was detected for the HVM34, HVM49 and HVM60 loci in the TB accessions, the HVM64 locus in the $\mathrm{QH}$ accessions and the HVM23, HVM49 and HVM64 loci in the GZ accessions. The average number of alleles per locus and standard deviation (SD) of the three subgroups were as follows: TB $(5.51 \pm 3.17)>\mathrm{QH}(5.14 \pm 2.88)>\mathrm{GZ}(4.34 \pm 2.72)$. Of the 248 alleles, 119 (47.98\%) were common to the three subgroups (common alleles) and the average number of common alleles was $3.40 \pm 2.66$, with the highest number of 
Table 3 - Allele sizes in base-pairs (bp), total number of alleles and number of common and private simple sequence repeat (SSR) for three subgroups of cultivated six-rowed naked barley (nudum barley) collected from Tibet (TB), Qinghai (QH) and Ganzi (GZ) in the Qinghai-Tibet plateau of China.

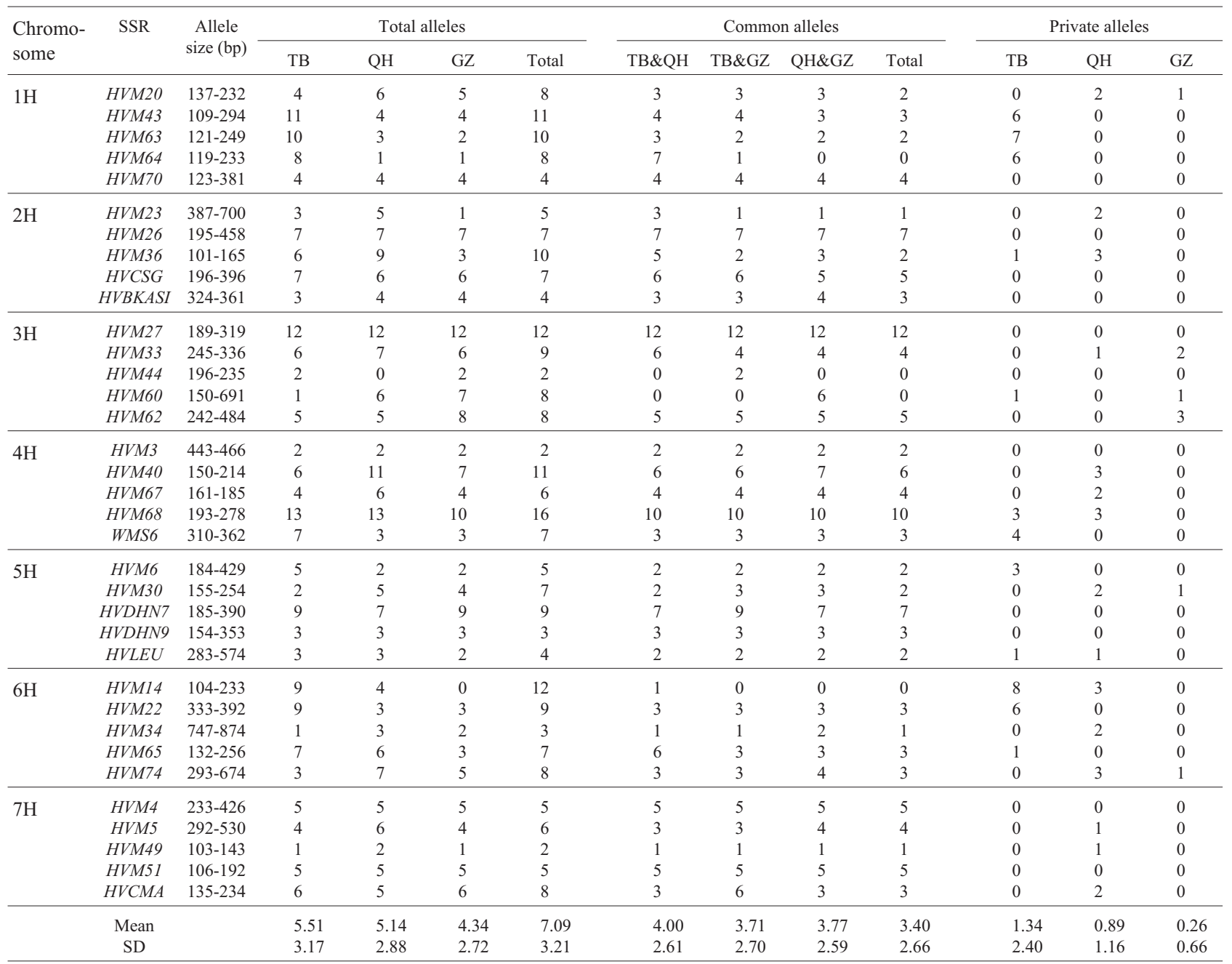

common alleles (12) being detected at the HVM27 locus while no common alleles were detected at the HVM14, HVM44, HVM60 and HVM64 loci. The number of alleles to specific private alleles per locus varied significantly among the three geographical subgroups with an average of 1.34 in $\mathrm{TB}, 0.89$ in $\mathrm{QH}$ and 0.26 in $\mathrm{GZ}$.

\section{Comparison of genetic diversity}

Table 4 presents the statistics relating to the genetic variation found at each locus. The average genetic diversity for the entire sample $\left(H_{T}\right)$ was 0.6594 whereas the mean value for the three geographical subgroups was as follows: $\mathrm{TB}=0.6172 ; \mathrm{QH}=0.4993 ;$ and $\mathrm{GZ}=0.4766$. There was a large variation in genetic diversity among the loci, the lowest diversity (0.1719) occurring at the HVM70 locus and the highest (0.9862) at the HVM14 locus. Genetic diversity in excess of 0.90 was found in eight loci in the TB subgroup, six in the QH subgroup and five in the GZ subgroup. Table 4 also shows that significant genetic diversity between the any two arbitrary-selected subgroups strongly depended on the loci involved. Genetic diversity in 10 of the 35 loci was in the order $\mathrm{TB}<\mathrm{QH}$, with only the HVM74 showing no difference between $\mathrm{TB}$ and $\mathrm{QH}$, while most loci $(66.7 \%)$ showed a significant difference in the order TB $>$ QH. We also found that 16 loci showed significantly larger genetic diversity in the TB and $\mathrm{QH}$ subgroups than in the GZ subgroup while only seven loci displayed obviously lower genetic diversity in the TB and QH subgroups than in the GZ subgroup. Similarly, 13 loci in the QH subgroup showed significantly larger genetic diversity than in the GZ subgroup whereas 11 loci in the QH subgroup presented significantly less genetic diversity than in the GZ subgroup. No difference was observed at the HVM70 locus in respect of the QH and GZ subgroups. Generally, the genetic diversity among the three subgroups was in the order $\mathrm{TB}>\mathrm{QH}>\mathrm{GZ}$ and, on average, genetic diversity in the TB subgroup accessions was significantly larger than in either the QH or GZ subgroups whereas there was no significant difference between the amount of genetic diversity in the $\mathrm{QH}$ and GZ subgroup accessions. 
Geographical differentiation and distribution of allelic frequencies

The total genetic diversity can be divided into withinand between-populations components, and in our case the proportion of each component varied from locus to locus. The genetic variation between subpopulations $\left(G_{S T}\right)$ reflects the geographical differentiation of samples, the amount of differentiation among the three subgroups varying from $0.27 \%$ at the $H V M 26$ locus to $55.52 \%$ at the HVM43 locus with an average of $18.58 \%$ and only five loci showing a $G_{S T}$ value of less than $5 \%$. The Chi-square test for the distribution of the allelic frequencies of the 35 loci among the three subgroups (Table 4) showed that two loci (HVM4 and HVDHN7) displayed significant differences $(\mathrm{p}<0.05)$ among the three subgroups and 23 loci highly

Table 4 - Genetic diversity, geographical differentiation $\left(G_{S T}\right)$ and allele frequency distribution $\left(\chi^{2}\right)$ for the 35 simple sequence repeat (SSR) loci among cultivated six-rowed naked barley (nudum barley) collected from Tibet (TB), Qinghai (QH) and Ganzi (GZ) in the Qinghai-Tibet plateau of China.

\begin{tabular}{|c|c|c|c|c|c|c|c|c|c|c|}
\hline \multirow{2}{*}{$\begin{array}{l}\text { Chromo- } \\
\text { some }\end{array}$} & \multirow[t]{2}{*}{ SSR } & \multicolumn{4}{|c|}{ Genetic diversity } & \multicolumn{3}{|c|}{ Difference } & \multirow[t]{2}{*}{$G_{S T}(\%)$} & \multirow[t]{2}{*}{$\chi^{2}$} \\
\hline & & $\mathrm{TB}$ & $\mathrm{QH}$ & GZ & $H_{T}$ & TB-QH & TB-GZ & QH-GZ & & \\
\hline \multirow[t]{5}{*}{$1 \mathrm{H}$} & HVM20 & 0.5968 & 0.6575 & 0.6100 & 0.6871 & -0.0607 & -0.0132 & 0.0475 & 9.84 & $25.98 * *$ \\
\hline & $H V M 43$ & 0.2752 & 0.0200 & 0.6175 & 0.6790 & $0.2552 * *$ & $-0.3423 * *$ & $-0.5975 * *$ & 55.52 & $108.96^{* *}$ \\
\hline & HVM63 & 0.2112 & 0.3050 & 0.5650 & 0.5297 & -0.0938 & $-0.3538 * *$ & $-0.2600 * *$ & 34.13 & $48.75^{* *}$ \\
\hline & HVM64 & 0.9920 & 0.9775 & 0.9975 & 0.8394 & 0.0145 & -0.0055 & -0.0200 & 2.68 & $87.89 * *$ \\
\hline & HVM70 & 0 & 0.2775 & 0.2775 & 0.1719 & $0.2775 * *$ & $-0.2775^{* *}$ & 0 & 0.64 & 1.04 \\
\hline \multirow[t]{5}{*}{$2 \mathrm{H}$} & $H V M 23$ & 0.3824 & 0.4575 & 0.8775 & 0.6625 & -0.0751 & $-0.4951 * *$ & $-0.4200 * *$ & 15.79 & $35.26 * *$ \\
\hline & $H V M 26$ & 0.2944 & 0.2775 & 0.1900 & 0.2578 & 0.0169 & $0.1044 *$ & 0.0875 & 0.27 & 0.93 \\
\hline & HVM36 & 0.3984 & 0.1650 & 0.3575 & 0.4457 & $0.2334 *$ & 0.0409 & $-0.1925^{*}$ & 29.55 & $46.11 * *$ \\
\hline & $H V C S G$ & 0.2576 & 0.4225 & 0.5425 & 0.4309 & $-0.1649 *$ & $-0.2849 * *$ & $-0.1200 *$ & 8.10 & 16.99 \\
\hline & $H V B K A S I$ & 0.9968 & 0.1450 & 0.9700 & 0.8671 & $0.8518 * *$ & 0.0268 & $-0.8250 * *$ & 16.22 & $45.50 * *$ \\
\hline \multirow[t]{5}{*}{$3 \mathrm{H}$} & $H V M 27$ & 0.5680 & 0.1475 & 0.1075 & 0.4811 & $0.4205 * *$ & $0.4605 * *$ & 0.0400 & 38.29 & $46.02 * *$ \\
\hline & HVM33 & 0.7968 & 0.5625 & 0.7700 & 0.7807 & $0.2343 * *$ & 0.0268 & $-0.2075^{* *}$ & 8.22 & $34.42 * *$ \\
\hline & $H V M 44$ & 0.0784 & 0.9800 & 0.0975 & 0.5644 & $-0.9016^{* *}$ & -0.0191 & $0.8825 * *$ & 35.91 & $38.32 * *$ \\
\hline & HVM60 & 0.9936 & 0.6700 & 0.8400 & 0.9352 & $0.3236 * *$ & $0.1536^{*}$ & $-0.1700 *$ & 9.45 & $51.89 * *$ \\
\hline & HVM62 & 0.4016 & 0.3900 & 0.0475 & 0.6263 & 0.0116 & $0.3541 * *$ & $0.3425 * *$ & 44.39 & $49.76^{* *}$ \\
\hline \multirow[t]{5}{*}{$4 \mathrm{H}$} & $H V M 3$ & 0.7296 & 0.6375 & 0.6750 & 0.7560 & 0.0921 & 0.0546 & -0.0375 & 9.46 & $15.44 * *$ \\
\hline & $H V M 40$ & 0.9936 & 0.3059 & 0.1784 & 0.9508 & $0.6877 * *$ & $0.8152 * *$ & $0.1275^{*}$ & 34.67 & $51.60 * *$ \\
\hline & HVM67 & 0.7984 & 0.7125 & 0.2525 & 0.6875 & 0.0859 & $0.5459 * *$ & $0.4600 * *$ & 12.15 & $58.03 * *$ \\
\hline & HVM68 & 0.2464 & 0.1400 & 0.1000 & 0.2982 & 0.1064 & $0.1464 *$ & 0.0400 & 43.46 & $55.68 * *$ \\
\hline & WMS6 & 0.9408 & 0.0925 & 0.9325 & 0.7946 & $0.8483^{* *}$ & 0.0083 & $-0.8400 * *$ & 14.78 & $37.02 * *$ \\
\hline \multirow[t]{5}{*}{$5 \mathrm{H}$} & HVM6 & 0.6448 & 0.9800 & 0.8000 & 0.9448 & $-0.3352 * *$ & $-0.1552 *$ & $0.1800 * *$ & 15.78 & $31.91 * *$ \\
\hline & HVM30 & 0.8400 & 0.6325 & 0.0775 & 0.6001 & $0.2075^{* *}$ & $0.7625^{* *}$ & $0.5550 * *$ & 9.77 & 20.13 \\
\hline & $H V D H N 7$ & 0.3808 & 0.5125 & 0.6750 & 0.6345 & $-0.1317 *$ & $-0.2942 * *$ & $-0.1625 *$ & 9.56 & $26.97 *$ \\
\hline & HVDHN9 & 0.8976 & 0.9600 & 0.8400 & 0.9039 & -0.0624 & 0.0576 & $0.1200 *$ & 0.53 & 1.64 \\
\hline & HVLEU & 0.8400 & 0.1700 & 0.0950 & 0.8610 & $0.6700 * *$ & $0.7450 * *$ & 0.0750 & 53.01 & $42.39 * *$ \\
\hline \multirow[t]{5}{*}{$6 \mathrm{H}$} & HVMI4 & 0.9230 & 0.9900 & 0.9000 & 0.9862 & -0.0670 & 0.0230 & 0.0900 & 5.04 & 30.43 \\
\hline & $H V M 22$ & 0.8681 & 0.7523 & 0.2800 & 0.7112 & $0.1158 *$ & $0.5881 * *$ & $0.4723 * *$ & 8.39 & 16.36 \\
\hline & HVM34 & 0.6400 & 0.6350 & 0.4550 & 0.6143 & 0.0050 & $0.1850^{*}$ & $0.1800 * *$ & 5.34 & 3.14 \\
\hline & HVM65 & 0.6368 & 0.9500 & 0.2300 & 0.7195 & $-0.3132 * *$ & $0.4068 * *$ & $0.7200 * *$ & 15.50 & $95.60 * *$ \\
\hline & $H V M 74$ & 0.6400 & 0.6400 & 0.3625 & 0.6400 & 0 & $0.2775^{* *}$ & $0.2775^{* *}$ & 13.34 & $30.79 * *$ \\
\hline \multirow[t]{7}{*}{$7 \mathrm{H}$} & HVM4 & 0.3312 & 0.0750 & 0.0825 & 0.2583 & $0.2562 * *$ & $0.2487 * *$ & -0.0075 & 31.90 & $17.63 *$ \\
\hline & HVM5 & 0.9168 & 0.5025 & 0.1325 & 0.8598 & $0.4143 * *$ & $0.7843 * *$ & $0.3700 * *$ & 36.26 & $35.97 * *$ \\
\hline & HVM49 & 0.9744 & 0.4950 & 0.9975 & 0.9179 & $0.4794 * *$ & -0.0231 & $-0.5025^{* *}$ & 9.14 & $31.24 * *$ \\
\hline & HVM51 & 0.5392 & 0.4200 & 0.2550 & 0.4620 & $0.1192 *$ & $0.2842 * *$ & $0.1650^{*}$ & 10.15 & 7.12 \\
\hline & HVCMA & 0.5760 & 0.4175 & 0.4925 & 0.5177 & $0.1585^{*}$ & 0.0835 & -0.0750 & 3.13 & 22.11 \\
\hline & Mean & 0.6172 & 0.4993 & 0.4766 & 0.6594 & $0.1179 * *$ & $0.1406 * *$ & 0.0227 & 18.58 & \\
\hline & SD & 0.2934 & 0.2956 & 0.3226 & 0.2166 & & & & 15.78 & \\
\hline
\end{tabular}

*Significant by the Z-test at $\mathrm{p}<0.05$; **Significant by the Z-test at $\mathrm{p}<0.01$. 
significant differences $(\mathrm{p}<0.01)$, whereas ten loci showed no clear differences in their distribution among the three subgroups. These results clearly show that there exists significantly geographical differentiation among the three subgroups.

\section{Cluster analysis}

In order to reveal genetic relationships of 65 accessions of cultivated six-rowed naked barley (nudum barley) landraces from the Qinghai-Tibet plateau of China, the genetic similarity coefficients between accessions were calculated and a dendrogram was constructed depicting the relationships between the accessions (Figure 1). At a genetic similarity level of about 0.76 the accessions were clearly clustered into two large groups (Cluster I and cluster II) with all the TB accessions being located in cluster I while, except for accession QH132, the QH and GZ accessions were located in cluster II. At a genetic similarity of about 0.79 the accessions were clustered in five large groups (A, B, C, D and E, Figure 1), all the TB accessions being clustered in groups $\mathrm{A}, \mathrm{B}$ and $\mathrm{C}$ while 13 of the $20 \mathrm{QH}$ accessions and all $20 \mathrm{GZ}$ accessions were clustered together in group $\mathrm{D}$, with the four accessions from Chengduo county and the two accessions from Maqin county (both counties in Qinghai province, i.e. QH accessions) being separately clustered in group E (Figure 1). In group D the $\mathrm{QH}$ and GZ accessions were clustered into their own separate groups at a genetic similarity level of 0.8 (Figure 1). These results clearly reveal the geographical differentiation of nudum barley landraces in the Qinghai-Tibet plateau and their genetic relationship.

\section{Discussion}

In this study, we investigated the genetic variation among 65 nudum barley landraces at 35 SSR loci in the barley genome. There exists large genetic variation within and among the three geographical subgroups TB, QH and GZ. The genetic diversity was significantly higher in nudum barley from the TB region than it from either the QH or GZ regions while there was no significant difference in terms of genetic diversity between the QH and GZ barleys. The total number of alleles and their standard deviations (Table 3) were in the order $\mathrm{TB}>\mathrm{QH}>\mathrm{GZ}$, while the average genetic distance followed the order TB $(0.2071)>\mathrm{QH}$ $(0.2063)>\mathrm{GZ}(0.1640)$. In addition, $18.58 \%$ of the total variation accounted for by differentiation among the three subgroups. These results appear to be in basic agreement with the Chi-square test on the distribution of allele frequencies (Table 4). The number of common and private alleles (Table 3) also reflected a certain geographical differentiation among the three subgroups, possibly due to the different geographical and ecological factors in the different regions of the Qinghai-Tibet plateau. As mentioned above, all the Tibetan accessions were clustered into one group (Cluster I) at a genetic similarity level of about 0.76

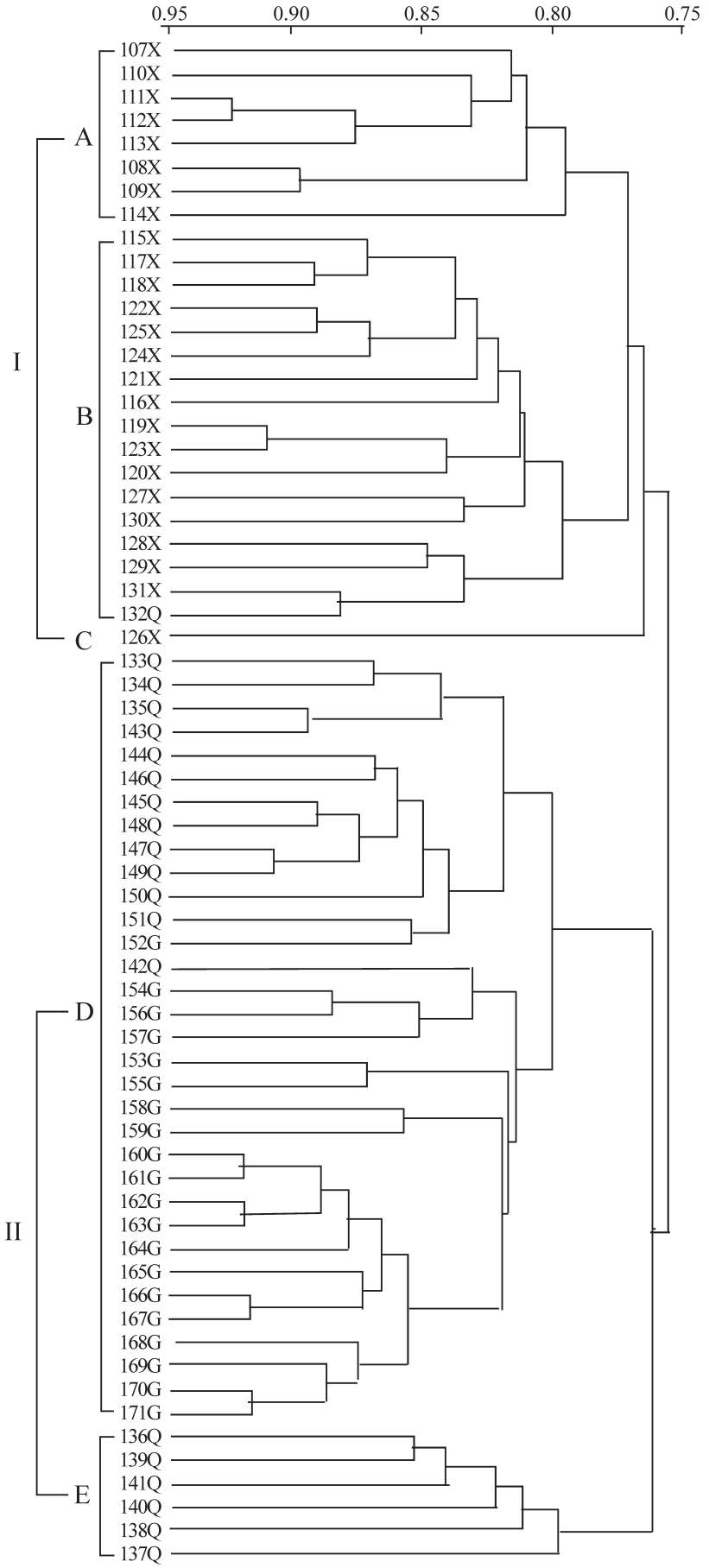

Figure 1 - Unweighted pair group method with averages (UPGMA) genetic similarity dendrogram of 65 cultivated six-rowed naked barley landraces from the Qinghai-Tibet plateau of China. Key: X = Tibet; $\mathrm{Q}=$ Qinghai; and $\mathrm{G}=$ Ganzi. See materials and methods for more details.

whereas the $\mathrm{QH}$ and $\mathrm{GZ}$ accessions (except the $\mathrm{QH} 132$ ) were grouped in cluster II.

Overall, our nudum barley data suggests that Tibet might be an original center of evolution of cultivated sixrowed naked barley which then spread to Qinghai and Ganzi prefecture in Sichuan province. Vavilov (1955) 
pointed out that the Middle-Western mountains of China were an original center of cultivated six-rowed naked barley. Previous morphological, ecological, distributional, archaeological and isozyme studies as well as genetics have shown that $H$. spontaneum in Tibet was the ultimate ancestor of Chinese cultivated barley whereas $H$. agriocrithon was an intermediate form in the transformation from $H$. spontaneum to cultivated barley (Xu, 1982).

Recently, our results on Tibetan wild barley using SSR markers also indicated that the Shannan region in Tibet might be the original center of Tibetan two-rowed wild barley (Feng et al., 2003) and Hordeum lagunculiforme in Tibet an intermediate form in the transformation from $H$. spontaneum to H. agriocrithon (unpublished data). Dai and Zhang (1989) studied the genetic diversity of six isozyme loci in cultivated barley from different agro-geographical regions in Tibet and found that the degree of genetic diversity was significantly higher in Tibetan cultivated barley than Ethiopia barley using the same 6 isozyme loci (Zhang et al., 1992a). Li et al. (2003) also supported the notion of Tibet being a center of genetic diversity for cultivated barley.

In conclusion, our SSR analysis of the 65 accessions of $H$. v. hexastichon var. nudum Hsü six-rowed naked barley from the Qinghai-Tibet plateau showed that the nudum barley landraces in Tibet possessed generally higher genetic diversity than those in Qinghai and Ganzi, with about $19 \%$ of the genetic diversity being accounted for by geographical differentiation among the three subgroups. This suggests that Tibet might be a center of genetic diversity of cultivated barley and that the cultivated six-rowed naked barley on the Qinghai-Tibet plateau of China might have evolved in Tibet and spread to Qinghai and then to Ganzi prefecture of Sichuan province.

\section{Acknowledgments}

The authors thank Prof. Ting-Wen Xu (Sichuan Agricultural University, China) for his critical reading of the manuscript, and Wen-Juan Zhou (Institute of Genetics \& Developmental Biology, Chinese Academy of Sciences) for her useful assistance. The research was supported by a grant from the Chinese Academy of Sciences (KSCX2SW-304), Program for Changjiang Scholars and Innovative Research in University (IRT0453), Sichuan Education Department and Sichuan Science and Technology Department of China.

\section{References}

Åberg E (1938) Hordeum agriocrithon, a wild six-rowed barley. Ann Agric Sweden 6:159-216.

Bassam B, Caetano-Anolles G and Gresshoffet P (1991) Fast and sensitive silver staining of DNA in polyacrylamide gels. Anal Biochem 196:81-84.

Brücher H and Åberg E (1950) Die-primitiv-gersten des hochlands von Tibet, ihre bedeutung fuer die zuechtung und das verstandis des ursprungs und der klassifizierung der gersten. Ann KGL Landwei Hochsch Schwedens 17:247319.

Dai XK and Zhang QF (1989) Genetic diversity of six isozyme loci in cultivated barley of Tibet. Theor Appl Genet 78:281286.

Davila J, Sanchez de la Hoz M, Loarce Y and Ferrer E (1998) The use of random amplified microsatellite polymorphic DNA and coefficients of parentage to determine genetic relationships in barley. Genome 41:477-486.

De Bustos A, Soler C and Jouve N (1999) Analysis by PCR-based markers using designed primers to study relationships between species of Hordum (Poaceae). Genome 4:129-138.

Feng ZY, Zhang YZ and Ling HQ (2002) Microsatellite markers and applications in the barley. Hereditas 24:727-733.

Feng ZY, Zhang YZ, Zhang LL and Ling HQ (2003) Genetic diversity and geographical differentiation of Hordeum vulgare ssp. spontaneum in Tibet using microsatellite markers. High Technology Letters 13:46-53.

Fernández ME, Figueiras AM and Benitoc (2002) The use of ISSR and RAPD markers for detecting DNA polymorphism, genotype identification and genetic diversity among barley cultivars with known origin. Theor Appl Genet 104:845851.

Fu DX, Xu TW and Feng ZY (2000) The ancient carbonized barley (Hordeum vulagre L. var. nudum) kernel discovered in the middle of Yalu Tsanypo river basin in Tibet. Southwest Chin J of Agri Sci 13:38-41.

Harlan JR (1976) Barley. In: Simmonds N (ed) Evolution of Crop Plants. Academic Press, London and New York, pp 93-98.

Hong QB, Hou L, Luo XY, Li DM, Xiao YH, Pei Y, Yang KJ and Jia C (2001) Using RAPD for evaluating genetic background among naked barley varieties in Sichuan northwestern region. Scientia Agricultura Sinica 34:133-138.

Li X, Xu C and Zhang QF (2003) Ribosomal DNA spacer-length polymorphisms in three samples of wild and cultivated barleys and their relevance to the origin of cultivated barley. Plant Breed 122:1-5.

Liu ZW, Biyashev RM and Saghai-Maroof MA (1996) Development of simple sequence repeat DNA markers and their integration into a barley linkage map. Theor Appl Genet 93:869-876.

Molina-Cano JL, Moralejo M, Igartua E and Romagosa I (1999) Further evidence supporting Morocco as a centre of origin of barley. Theor Appl Genet 98:913-918.

Nei M (1973) Analysis of gene diversity in subdivided populations. Proc Natl Acad Sci USA 70:3321-3323.

Pau G and Southern EM (1982) Electrophoresis of DNA. In: Rickwood D and Hames BD (eds) Gel Electrophoresis of Nucleic Acids: A Practical Approach. IRL Press Limited, Oxford and Washington DC, pp 39-75.

Rohlf FJ (1993) NTSYS-pc, Numerical Taxonomy and Multivariate Analysis System. Applied Biostatics Incorporated, New York.

Rong TZ (1993) Chi-square test. In: Rong TZ (ed) Agricultural Experiments and Statistical Analysis. 1st edition. Sichuan Sci \& Tech Press, Chengdu, China, pp 85-90.

Russell JR, Fuller JD, Young G, Thomas B, Taramino G, Macaulay M, Waugh R and Powell W (1997) Discriminating between barley genotypes using microsatellite markers. Genome 40:442-450. 
Saghai-Maroof MA, Biyashev RM, Yang GP, Zhang QF and Allard AW (1994) Extraordinarily polymorphic microsate1lite DNA in barley: Species diversity, chromosomal locations, and population dynamics. Proc Natl Acad Sci USA 91:5466-5470.

Shao QQ (1982) Wild Barley of Tibet. 1st edition. Scientific Press, Beijing, pp 1-86.

Shao QQ, Li AS and Zhou ZQ (1986) Genetic distance between cultivated barley and its wild relatives. In: Chinese Barley Special Committee (ed) Proceedings of Chinese Barley Science. Chin Agri Sci \& Tech Press, Beijing, pp 22-23.

Stein N, Herren G and Keller B (2001) A new DNA extraction method for high-throughput marker analysis in a large-genome species such as Triticum aestivum. Plant Breed 120:354-356.

Sun LJ, Gao JY and Guan JP (1995) Diversity of esterase isozyme and its geographical distribution in barley of China. Crop Genetic Resources 2:1-5.

Vavilov NI (1926) Studies on the origin of cultivated plants. Bull Appl Bot Genet Plant Breed USSR 16:1-248.

Xu TW (1975) On the origin and phylogeny of cultivated barley with reference to the discovery of Ganzi wild two-rowed barley Hordeum spontaneum C. Koch. Acta Genetica Sinica 2:129-137.

Xu TW (1982) Origin and evolution of cultivated barley in China. Acta Genetica Sinica 9:440-446.

Xu TW (1986) Origin and phylogeny of cultivated barley in China. In: Proceedings of Chinese Barley Science. Chin Agri Sci \& Tech Press, Beijing, pp 34-44.
Xu TW and Feng ZY (2001) On the origin of cultivated barley in China with reference to the explanations of the Chinese classical words Lai Mu. Southwest Chin J of Agric Sci 14:102104.

Yao Z (1982) Study on N-bands of chromosomes in wild and cultivated barley. Acta Genetica Sinica 9:160-164.

Zhang QF and Allard RW (1986) Sampling variance of the genetic diversity index. J Heredity 77:54-55.

Zhang QF, Dai XK and Saghai-Maroof MA (1992a) Comparative assessment of genetic variation at 6 isozyme loci in barley from two centers of diversity. Ethiopia and Tibet. Chin J Genet 19:119-126.

Zhang QF, Saghai-Maroof MA and Yang GP (1992b) Ribosomal DNA polymorphisms and the Oriental-Occidental genetic differentiation in cultivated barley. Theor Appl Genet 84:682-687.

Zhang QF, Yang GP, Dai XK and Sun JZ (1994) A comparative analysis of genetic polymorphism in wild and cultivated barley from Tibet using isozyme and ribosomal DNA markers. Genome 37:631-638.

Zhang XY, Li CW, Wang LF, Wang HM, You GX and Dong YS (2002) An estimation of the minimum number of SSR alleles needed to reveal genetic relationships in wheat varieties. I. Information from large-scale planted varieties and cornerstone breeding parents in Chinese wheat improvement and production. Theor Appl Genet 106:112-117.

Zhou ZQ (1981) Comparison between the two-rowed wild barley of Qing-Zang plateau and of Israel. Acta Genetica Sinica 8:344-349.

Associate Editor: Márcio de Castro Souza Filho 